\title{
Design Requirements for a Teledermatology Scale-up Framework
}

\author{
Laticha E.M. Walters ${ }^{\mathrm{a}, \mathrm{b}}$, Richard E. Scott ${ }^{\mathrm{a}, \mathrm{c}, \mathrm{d}}$, Maurice Mars ${ }^{\mathrm{a}}$ \\ ${ }^{a}$ Department of TeleHealth, Nelson R. Mandela School of Medicine, University of KwaZulu-Natal, South Africa \\ ${ }^{b}$ Council for Scientific and Industrial Research, Meraka Institute, South Africa \\ c Department of Community Health Sciences, University of Calgary, Canada \\ ${ }^{\text {d }}$ NT Consulting—Global e-Health Inc., Calgary, Canada
}

\begin{abstract}
The value proposition of full-scale teledermatology is evidenced in the literature. The public health sector of South Africa's KwaZulu-Natal province began synchronous teledermatology in 2003, followed by spontaneous asynchronous (mobile) teledermatology in 2013. No scale-up has been formally planned. This paper establishes design requirements that will inform the identification or de novo development of a teledermatology scale-up framework.

Methods: A requirements definition process with inductive reasoning approaches was applied. Analysis of semistructured interviews (19) with key teledermatology stakeholders (17) and observations from two teledermatology programmes, informed by lessons learned from prior teledermatology implementation attempts, eHealth scale-up literature and authors' expert opinion, led to identification of themes, and iterative reflection gave rise to categories and requirements.

Results: Teledermatology scale-up framework design requirements emerged comprised of themes (4), categories (12), and specific design requirements (30).

Discussion: This paper describes a process and resulting evidence-based (stakeholder interviews; programme observations; literature) and experience-based (expert opinion) design requirements to inform the identification and adoption / adaptation or de novo development of a Teledermatology Scale-up Framework (TDSF) for KwaZuluNatal's public health sector. The proposed approach is recommended as a pre-requisite for scaling, including in other settings and for other telehealth applications.
\end{abstract}

Keywords: Teledermatology, scale-up framework, requirements definition, requirements elicitation, South Africa Categories: • General computing $\sim$ Applied computing

Email:

Laticha E.M. Walters Iwalters@csir.co.za (CORRESPONDING)

\section{Article history:}

Received: 9 November 2017

Accepted: 13 May 2018

Available online: 10 July 2018

\section{INTRODUCTION}

Determining design requirements is fundamental to any eHealth intervention or activity. A 'requirement' (Institute of Electrical and Electronics Engineers, 2011) is a physical or functional

Walters, L.E.M., Scott, R.E., and Mars, M. (2018). Design Requirements for a Teledermatology Scale-up Framework. South African Computer Journal 30(1), 128-160. https://doi.org/10.18489/sacj.v30i1.559

Copyright (C) the author(s); published under a Creative Commons NonCommercial 4.0 License (CC BY-NC 4.0). $S A C J$ is a publication of the South African Institute of Computer Scientists and Information Technologists. ISSN 1015-7999 (print) ISSN 2313-7835 (online). 
need that a particular process or framework intends to satisfy in order to be successful. This paper presents the identification of design requirements to inform the identification or development of a Teledermatology Scale-up Framework (TDSF). The process used elements of a published requirements definition process (Institute of Electrical and Electronics Engineers, 2011) and insight gained from multiple sources (key Teledermatology (TD) stakeholder interviews, TD programme observation, TD scale-up or related literature, and expert opinion), and then triangulated to verify their relevance. The importance of this approach was to ensure that the envisioned TDSF met the TD scale-up needs of stakeholders (internal requirements) whilst ensuring alignment with the literature, government policy and strategic direction (external requirements) (Simon, 1996, p. 113).

In this study, the term scale-up refers to the World Health Organization's definition:

deliberate efforts to increase the impact of successfully tested health innovations so as to benefit more people and to foster policy and programme development. (World Health Organization, 2010a, p. 2)

Additionally, the term framework refers to a tool that systematically guides the planning and implementation processes, leading to sustained practice (World Health Organization, 2010a). Finally, in this paper these are aligned specifically with Teledermatology (TD).

TD refers to the delivery of dermatologic care via the use of information and communication technology (American Telemedicine Association, 2016). TD is effective in enhancing access to scarce dermatologists (Bashshur, Shannon, Tejasvi, Kvedar, \& Gates, 2015). TD is mostly provided using asynchronous (store and forward) methods in which messages and photographs are sent by e-mail, text messaging, or to a secure web site with dermatologists responding at a later time (American Telemedicine Association, 2017; Mars, 2013). It may also be provided synchronously (in real time) using live interactive videoconferencing (American Telemedicine Association, 2017). A combination of both is also possible (Mars, 2013; Office for the Advancement of Telehealth, 2015). For example a synchronous videoconference-based TD service enables clinicians with patients in attendance from rural referring hospitals to consult with dermatologists located at the central referral hospital without the participants (from referring and referral hospitals) being in the same physical location. The current TD programme have reduced appointments from a waiting period of up to four months to one month (KwaZulu-Natal, stakeholder interviews).

Bashshur et al. (2015) provide support for TD 's value contribution: diagnostic and treatment concordance, skin care delivered by primary care physicians, and cost savings. The value contribution of full-scale TD is also supported by several studies from USA, UK and Europe (Coates, Kvedar, \& Granstein, 2015a, 2015b; Cruickshank \& Beer, 2010). Despite this, scale-up of TD remains largely elusive (Mars, 2013) with the exception of the Netherlands and some states and the Veterans Administration (VA) in the USA (Tensen, van der Heijden, Jaspers, \& Witkamp, 2016).

The failure to achieve the value contribution of full-scale TD also applies to South Africa. Earlier work described the fundamentals and lessons learned to inform a scale-up framework for teledermatology (Walters, Mars, \& Scott, 2016). The fundamentals provided initial input 
to the design requirements definition process, but to fully inform a TD scale-up framework a more extensive understanding of these design requirements was necessary. This paper extends earlier work (Walters et al., 2016) by presenting a TD scale-up framework requirements definition process based on IEC/IEEE 29148:2011(E) (2011) and describing the resulting evidence-based design requirements. Insight was gained from multiple sources (key TD stakeholder interviews, TD programme observation, TD scale-up or related literature, and expert opinion), and triangulated to validate data through cross verification from two or more sources. The importance of these approaches was to ensure that the envisioned TDSF was evidence-based and met the TD scaleup needs of stakeholders (internal requirements) whilst ensuring alignment with the literature, government policy and strategic direction (external requirements) (Simon, 1996, p. 113). Section 2 provides the background on TD in South Africa and why a requirements definition process was necessary to establish design requirements. Section 3 provides the research methods, followed by Section 4 that describes the resulting design requirements. Section 5 completes the paper with a discussion of the design requirements followed by Section 6 with concluding comments.

\section{BACKGROUND}

\subsection{Teledermatology in South Africa}

A recent study of TD in the South African public health sector (Walters et al., 2016) found that although synchronous (real-time interactive) and asynchronous (store-and-forward) TD have been in use, there was no evidence of a fully scaled-up service (Naidoo \& Mars, 2015).

Phase one of the National Telemedicine System for the public sector in South Africa started in 1999 (Gulube et al., 1999) with TD earmarked for subsequent phases. The programme did not proceed beyond phase one of the three planned phases (Gulube \& Wynchank, 2001, 2002). There are currently active TD programmes in two of the nine South African Provinces, the Western Cape and KwaZulu-Natal, neither of which have been scaled-up to serve all of those hospitals without a resident dermatologist (Walters et al., 2016).

For example, there are two active services in KwaZulu-Natal, a synchronous videoconferencebased service and an asynchronous mobile phone-based service. The synchronous service started in 2003, and operates between three rural district hospitals and the local medical school (Mars \& Dlova, 2008). The asynchronous service began spontaneously in 2013 with several rural hospitals using mobile phones and instant messaging (WhatsApp) (Mars \& Scott, 2017) to send text messages and photographs, or emails, to the medical school (Mars \& Scott, 2015b, 2015a). The scale-up of both of these services could potentially benefit 68 (of 74) hospitals in the Province without a resident dermatologist.

To assist with the scale-up of TD services there is a need for a holistic Teledermatology Scaleup Framework (TDSF), which could be applied to all public sector hospitals (Walters et al., 2016). The Walters et al. (2016) study proposed the development of a TDSF to:

contribute towards equitable dermatologist access through an efficient, effective, and sustainable referral service delivery intervention 
which would enable the widespread integration and operationalisation (scale-up) of TD in the public health sector (Walters et al., 2016, p. 149). The study identified the fundamentals, including embracing bottom-up provincial progress, ensuring alignment with government top-down approaches, meeting an evidenced-based health need, ensuring cultural and technological readiness, ensuring leadership and stakeholder buy-in, providing business and financial planning, and service monitoring (Walters et al., 2016). In addition records from the literature review of Walters et al. (2016) contributed to the lessons learned (the literature) for this study.

Further work was required to determine more extensive and substantiated design requirements to inform a TDSF.

\subsection{Design requirements for a teledermatology scale-up framework (TDSF)}

Determining design requirements is fundamental to any eHealth intervention or activity. Van Velsen, Wentzel, and Van Gemert-Pijnen (2013) supported the requirements definition approach for eHealth developers by providing insight into activities for functional and non-functional requirements identification, communication and evaluation, while Barker, Reid, and Schall (2016) presented design features. However, actual design requirements for TD or related scale-up framework development are not addressed in literature.

In order to identify and define design requirements for the development of a TDSF, this paper presents a requirements definition process and describes the resulting design requirements. The derived design requirements will be used to inform the identification and adoption / modification or de novo development of a TDSF as envisaged in Walters et al. (2016).

\section{RESEARCH METHODS}

A qualitative study was undertaken between 2014 and 2016 to understand stakeholder needs, programme processes, scale-up and related literature, and to apply expert opinion to identify and define design requirements that inform a TDSF. Data collection used semi-structured interviews for stakeholder needs (interviews), clinic site visits for TD programme observation (observations), and literature review (including from a recent study (Walters et al., 2016)) for lessons learned (the literature), plus authors' health information systems and ehealth experience for expert opinion. The data was analysed using an inductive approach (Saunders, Lewis, \& Thornhill, 2016) through an iterative process of continuously re-examining the data for the emergence of design requirements, categories and themes. A design requirement was considered if supporting evidence from two or more sources could be obtained (i.e., triangulated) (Thurmond, 2001). Stakeholder and TD programme information was collected in two stages. The first stage (2014) obtained initial insight using telephonic and face-to-face semi-structured interviews, while the second stage (2016) used additional stakeholders and stakeholder interviews to confirm initial insight. In addition context specific information about the dermatology clinic referral process was obtained by site visits and programme observation.

The literature review provided lessons learned from prior studies and was supplemented with 
considerations for IT governance, project management, and business process management. These insights were used to develop semi-structured interview guides for stakeholder interviews and perform observations of TD clinic processes. The design requirements definition process was initially based on selected elements from the stakeholder requirements definition process of ISO/IEC/IEEE 29148:2011(E) (2011), and followed three steps: elicit stakeholder requirements, define stakeholder requirements, and analyse stakeholder requirements.

Seventeen key TD stakeholders were interviewed and audio recorded / transcribed verbatim, and the operation of two TD clinics were observed. Participants were purposively selected from the KwaZulu-Natal Department of Health and the University of KwaZulu-Natal to be representative of individuals involved in the application of TD. These stakeholders were: two senior dermatologists in management roles, four dermatologists from the central urban receive site, three referring doctors from rural referring (send) sites, two technical managers and three technical support staff at the central urban referral site, an eHealth manager and IT governance manager from the provincial head-office, and a telehealth pioneer from the University of KwaZulu-Natal. The two sites - Port Shepstone Hospital, Ugu District, and Manguzi Hospital, Umkhanyakude Districtwere rural hospitals located $122 \mathrm{~km}$ and $421 \mathrm{~km}$ from the central urban referral site at the medical school in Durban.

A recent review and critique of attempts to implement and scale-up TD in South Africa provided 'lessons learned' from the literature and fundamental TDSF requirements (Walters et al., 2016). Thereafter, IT governance, IT project management, and business process management standards and frameworks were considered (based on an authors (LEMW) prior health information systems implementation and scale-up experience in Southern Africa's public health sector) were used to complete the interview schedule. Iterative and reflective thematic analysis of transcribed interviews and observations of TD programmes provided general patterns ${ }^{1}$. Additionally the practical and theoretical global experience of authors (RES and MM) was applied to consideration of each need. This overall approach allowed scale-up needs to be determined, placed in context, and then translated into clear themes, categories, and specific design requirements. In this way the requirements definition process was used to develop the TDSF design requirements and allocate them in a meaningful and evidence-based (stakeholder interviews, programme observation, the literature) and experience-based (authors' expert opinion) manner

Ethical clearance was granted by the Humanities and Social Sciences Research Ethics Committee of the University of KwaZulu-Natal and the KwaZulu-Natal Health Research Committee, and approved by the specific sites. Consent was obtained from individual interview participants.

\section{DESIGN REQUIREMENTS}

After progressive iterative analysis saw saturation (i.e., little change between subsequent versions), analysis was stopped. Four major themes emerged in the final iteration: Framework organisation, eHealth building blocks, eHealth planning, and eHealth action. Within each theme, categories

\footnotetext{
${ }^{1}$ NVivo for Mac version 11.4.0.
} 
were identified (12 in total), and specific design requirements were described (30 in total), each based on one or more of stakeholder interview (interviews), programme observation (observations), lessons learned from recent literature review (the literature), or expert opinion (Table 1). Themes, categories, and requirements are described below, and their sources of evidence summarised in Tables 2, 3, 4, and 5. In order to concisely present the findings, not every finding is explicitly described, instead illustrative examples have been provided, key sources of evidence are identified, and some verbatim responses from interviews are included. Confirmation of the fundamental need for a TDSF arose through the literature (Walters et al., 2016; World Health Organization, 2011) and interviews.

Table 1: List of themes, categories, and number of teledermatology (TD) design requirements per category

\begin{tabular}{llc}
\hline Themes (4) & Categories & $\begin{array}{c}\text { No. of TD design } \\
\text { requirements }\end{array}$ \\
\hline 4.1 Framework organisation & 4.1 .1 General design & 4 \\
\hline \multirow{4}{*}{4.2 eHealth building blocks } & 4.2 .1 eHealth need & 1 \\
& 4.2 .2 eHealth stakeholders & 1 \\
& 4.2 .3 eHealth strategy & 5 \\
& 4.2 .4 eHealth regulations & 2 \\
& 4.2 .5 eHealth governance & 1 \\
\hline \multirow{3}{*}{4.3 eHealth planning } & 4.3 .1 eHealth information systems & 4 \\
& 4.3 .2 eHealth sustainability & 3 \\
& 4.3 .3 eHealth benefits & 2 \\
& 4.3 .4 eHealth program management & 1 \\
\hline \multirow{2}{*}{4.4 eHealth action } & 4.4 .1 eHealth scale-up & 5 \\
& 4.4 .2 eHealth monitoring & 1 \\
\hline
\end{tabular}

\subsection{Theme: Framework organisation}

Framework organisation refers to the dependencies and relationships of the various categories and underlying design requirements that will be used to support the identification or development of a TDSF. A single category emerged from the study, 'General design', which was composed of 4 specific design requirements from different sources (Table 2):

1. Holistic concept and scope

2. Theoretical foundation

3. TD lessons learned

4. TD scale-up phases

Section 4.1.1 describes the detailed design requirements for the category 'General design'. 
Table 2: Summary of data sources that provided inputs to theme: 'Framework organisation' with supporting categories and detail requirements

\begin{tabular}{|c|c|c|c|c|c|}
\hline & Requirement name & Literature & Interviews & Observations & Expert opinion \\
\hline \multirow{4}{*}{ General design } & Holistic concept \& scope & $\checkmark$ & \multirow{4}{*}{$\checkmark$} & & $\checkmark$ \\
\hline & Theoretical foundation & $\checkmark$ & & & $\checkmark$ \\
\hline & TD lessons learned & $\checkmark$ & & & $\checkmark$ \\
\hline & TD scale-up phases & $\checkmark$ & & & $\checkmark$ \\
\hline
\end{tabular}

\subsubsection{Category: General design}

The literature indicated the approach to be adopted for TDSF design should be holistic in concept and scope (Van Dyk, 2014; Van Gemert-Pijnen et al., 2011), and further recommended that the TDSF should be aligned with existing or planned legal and regulatory public health structures (Walters et al., 2016; South African Bureau of Standards, 2016; South Africa Public Service and Administration, 2013; Health Professions Council of South Africa, 2014). Furthermore, recognising that a framework might exist that could simply be adopted, various sources of evidence (interviews, observation, the literature, and expert opinion on project management principles (Project Management Institute, 2017a)) indicated that such a framework must be proven and supported with real-world implementation results, rather than just theoretical in its basis.

TD holistic concept and scope: It is important that the envisioned TD scale-up framework addresses all aspects of the scale-up process. The literature indicates that scaling-up of an intervention cannot be done by focussing only on one implementation aspect or consideration, because healthcare is a complex system where implementation of an initiative in one location may have ripple effects in others. This highlights the need to adopt a holistic and integrated approach to the planning and scale-up of fixed and mobile TD and leads to identification of this design requirement (Van Dyk, 2014; Van Gemert-Pijnen et al., 2011; Cooley \& Kohl, 2006; World Health Organization, 2010a, p. 2).

TD theoretical foundation: Literature indicates the development of a TDSF should be based on a theoretical foundation (Walters et al., 2016). This provides a scientific grounding and paradigm to guide the development or identification of the TDSF using recognised research methods.

TD lessons learned: Examination of existing and related eHealth, mHealth, or Telehealthrelated frameworks provided real-world implementation lessons. For example, within South Africa, reasons for failure of the National Telemedicine System were documented to include the shortage of healthcare workers, the reluctance of existing healthcare workers to take on additional work, the top-down approach taken, a pervasive lack of capacity, and the failure to manage change (Mars \& Seebregts, 2008). Outside of South Africa, the success of teleradiology services (the most successful telemedicine sub-speciality) has been attributed to being standards based (Tyler, 2001). 
In addition, various success factors have been described out of Australia and the European Union that provide additional lessons (Yellowlees, 2001; Christiansen et al., 2015; Yellowlees, 2002).

TD scale-up phases: Cooley and Kohl (2006) have shown that grouping of related activities and their associated steps can support scale-up process flow. Similarly Simmons, Fajans, and Ghiron (2007, p. xiv) advocate the "importance of scaling-up strategies that phase in change incrementally". Consequently, identifying TD scale-up phases as a design requirement will ensure that when a TDSF is selected or developed, it will introduce change in a series of phases that aid sequencing of implementation activities.

\subsection{Theme: eHealth building blocks}

Certain components must exist prior to proceeding with progressive steps towards scale-up, and these are described as 'building blocks'. The study findings identified five categories of building blocks, which should exist before attempting scale-up from different sources (Table 3); an eHealth need, eHealth stakeholders, an eHealth strategy, eHealth regulations, and an eHealth governance setting. These five categories contain a total of 10 design requirements. Sections 4.2.1 to 4.2.5 describe the detailed design requirements for all categories under the theme 'eHealth building blocks'.

Table 3: Summary of data sources that provided inputs to theme 'eHealth building blocks' with supporting categories and requirements

\begin{tabular}{|c|c|c|c|c|c|}
\hline & Requirement name & Literature & Interviews & Observations & Expert opinion \\
\hline eHealth need & TD scale-up need & $\checkmark$ & $\checkmark$ & $\checkmark$ & $\checkmark$ \\
\hline $\begin{array}{l}\text { eHealth } \\
\text { stakeholders }\end{array}$ & $\begin{array}{l}\text { TD stakeholder } \\
\text { management }\end{array}$ & $\checkmark$ & $\checkmark$ & $\checkmark$ & $\checkmark$ \\
\hline \multirow{5}{*}{$\begin{array}{l}\text { eHealth } \\
\text { strategy }\end{array}$} & TD scale-up strategy \& budget & $\checkmark$ & $\checkmark$ & $\checkmark$ & $\checkmark$ \\
\hline & TD environmental scan & $\checkmark$ & & & $\checkmark$ \\
\hline & TD change management & $\checkmark$ & $\checkmark$ & $\checkmark$ & $\checkmark$ \\
\hline & TD clinic setting & $\checkmark$ & $\checkmark$ & $\checkmark$ & $\checkmark$ \\
\hline & TD availability & $\checkmark$ & $\checkmark$ & $\checkmark$ & $\checkmark$ \\
\hline eHealth & TD regulations & $\checkmark$ & $\checkmark$ & $\checkmark$ & $\checkmark$ \\
\hline regulations & TD standards & $\checkmark$ & $\checkmark$ & $\checkmark$ & $\checkmark$ \\
\hline $\begin{array}{l}\text { eHealth } \\
\text { governance }\end{array}$ & TD alignment & $\checkmark$ & $\checkmark$ & $\checkmark$ & $\checkmark$ \\
\hline
\end{tabular}

\subsubsection{Category: eHealth need}

The literature refers to the importance of an eHealth intervention to address a clear health system need and priority of the institution, region or country (Hussein, 2015). Furthermore TD scale-up, is to be evidence-based, technologically appropriate and culturally sensitive (Scott \& Mars, 2013). Similarly, the TD scale-up design requirements must address a defined eHealth need. One design requirement 'TD scale-up need' was identified. 
TD scale-up need: The literature shows there is a lack of specialists, such as dermatologists, within South Africa and poor referral capability at this time (Carruthers, 2013; South Africa National Department of Health, 2012a), and that there has been a spontaneous adoption of mobile TD (Mars \& Scott, 2015a, 2015b, 2017). Other literature points to good concordance between diagnosis at dermatology clinics and diagnosis using TD and mobile TD (Mars \& Scott, 2015a, 2015b, 2017), although the need should be balanced with the available ICT coverage and capability (Clarke \& Mars, 2015). Collectively these findings support the need for scale-up of TD.

\subsubsection{Category: eHealth stakeholders}

Stakeholders can be any individual, organisation, group, or society at large that has an interest in or concern with an entity or activity, or who can affect or be affected by an entities actions, objectives or policies. In regard to eHealth, many stakeholders can exist, and it is important to identify each one and their particular interest in or effect upon the intended ehealth intervention, and to manage their expectations accordingly.

TD stakeholder management: Mars and Seebregts (2008) dentified that the private sector were not always included in government planning. The literature and expert opinion highlighted the need for broad and pre-existing stakeholder buy-in for any TD service. This buy-in must exist from planning through sustained implementation, and must flow from 'above' (government leaders) as well as from 'below' (users of the service). This can include a spectrum of individuals from healthcare practitioners, to administrators, to patients. Often such buy-in can be achieved through identification and influence of champions, and involvement of stakeholders, including the private sector, during engagement and consensus building activities (Jensen, Knarvik, Pedersen, Tangene, \& Whitehouse, 2015; Wade \& Eliott, 2012; Yellowlees, 2001, 2005).

Many stakeholder-related requirements were also identified during interviews and observations. These covered a broad range of issues from service hours, to technical support and data stewardship issues, to procedural aspects of service provision, and even to buy-in of stakeholders. From interviews, representative quotes from stakeholders focussed primarily on videoconferenced TD and not email or the more recent instant messaging TD, and included:

It must be available during the working hours 08:00 to 17:00. (Clinician)

There must be technical staff support on both ends. (Clinician)

Equipment maintenance both ends, there must be the stuff in terms of the wires whatever to ensure that the transmission is efficient and fast. (Clinician)

The Doctors who are seeing the patients must explain properly the process. (Clinician)

The patients are comfortable to undress in front of a camera. (Clinician) 
Network problem is a big issue. (Clinician)

Would appreciate dermascopes on occasion for the moles it could be useful. (Clinician)

and

I think it was not marketed adequately for people to understand the purpose and the importance of telehealth. (Administrator)

These collective findings indicated that mandated and committed leadership, supported by key stakeholder buy-in, is critical to successful implementation and scale-up. This led to recognition of the need to actively nurture stakeholder development, and to manage resulting stakeholder expectations.

\subsubsection{Category: eHealth strategy}

The literature has become replete in recent years with documents recommending and giving direction for development of eHealth specific strategies and associated budgets in order to facilitate implementation (Scott \& Mars, 2013). The same literature also notes that often such documents are not developed or are incomplete. The interviews also acknowledged this:

I have a plan. [But the] Plan is not approved [and] still in draft form. (Manager)

Within this larger concept of eHealth strategy is the need to understand how the process will occur for TD specifically. This is the goal of the larger body of research of which identifying design requirements for the identification or development of a TDSF is a part. Five design requirements were identified for the category of eHealth strategy:

1. TD scale-up strategy and budget,

2. TD environmental scan,

3. TD change management,

4. TD clinic setting, and

5. TD availability.

TD scale-up strategy and budget: A TD specific strategy (Scott \& Mars, 2013) and budget provides a management framework that ensures scale-up objectives are aligned with overall national and provincial eHealth strategic objectives, and provides a mandate for the development of detailed scale-up plans. The requirement for a clear strategy to identify the scale-up process for $\mathrm{TD}$, and for appropriate budget provision (defined, approved and implemented), was expressed by experts, and identified from interviews and the literature. For example, the literature promoted preparation and provision of plans and associated budgets as well as warning of the dangers of the 
current top-down planning (Mars \& Seebregts, 2008) and bottom-up implementation approach (Walters et al., 2016), and promoted organic and iterative processes (Barker et al., 2016). In response to the interview question for TD planning documentation and budget two participants also voiced concern and need for action:

It's all been just discussion, nothing has been documented. (Clinician)

We're basically, doing it gratis. (Clinician)

TD environmental scan: The need to gain current and complete insight of the environmental or contextual factors (Leigh-Hunt, 2016) that TD scale-up will be interacting with positively contributes to context-sensitive scale-up strategy planning. As long ago as 2003, Whitten and Adams noted:

It is crucial that the organization in which it is intended to launch telemedicine is examined carefully first. Each organization operates within a larger environment, which is often constrained by fiscal, geographical and personnel factors. (Whitten \& Adams, 2003, p. 125)

The literature also indicate that scaling-up can only be successful if it can be implemented and embedded within a setting that is open (Simmons et al., 2007) and ready (Khoja et al., 2007). To understand this it is necessary to conduct some form of situational assessment that provides context-sensitive insight.

TD change management: The adoption of an eHealth intervention without due consideration of TD's impact on existing routine operations could negatively affect its success. Over a decade ago Yellowlees stated:

Successfully developing telemedicine systems is primarily about effective change management. (2005)

Introducing and embedding TD through the consideration of practice guidelines (American Telemedicine Association, 2016; Schonenberg et al., 2014) will ensure the referral process becomes more efficient and effective. However, this will inevitably lead to changes in clinical and administrative processes as acknowledged in the literature:

While technology is an important feature of providing telehealth, the real impact is through the redesign of pathways. (Cruickshank \& Beer, 2010, p. 48)

impacting aspects that include workflow, workload, and staffing structures. These must be understood, and mechanisms designed, approved, and implemented that simplify and manage the changes. Recognition of this also arose during interviews: 
So we don't have a person dedicated to telederm, which would be ideal, if that's what they did, you know, even if it was on a rotational basis where we could link up with many sites and each day we do clinics. Certainly, staffing and manpower is an issue, because it takes so much of time. (Clinician)

and during observation of the TD programmes.

TD clinic setting: The literature and interview participants made comments regarding the physical setting of the TD clinic on both the rural referring and central urban referral site. Despite the fact that initial TD clinics were setup in dedicated rooms, programme observation showed this has since changed in some locations to multi-purpose rooms. The interview participants focussed on issues of patient privacy and confidentiality, stating:

There must also be the environment for patients on both ends, privacy curtains, special place for patients to feel comfortable to undress in front of a camera. (Clinician)

In contrast, the literature addressed more practical issues around lighting, placement of equipment, and wall colour (Major, 2005; Martin, 2011). All of these factors are relevant, and are encompassed in the design requirement 'TD clinic setting'.

TD availability: The National Health Insurance financing scheme which is in line with WHO universal health coverage aims to increase access to equitable healthcare (South Africa National Department of Health, 2017). Interviews and the literature addressed the issue of having the option to provide dermatology services at the nearest point of care. A key interview participant stated:

patients can be referred as such and of course patients also should have a choice if they want to be seen through TD or they want to be seen face to face. (Clinician)

As TD is scaled-up it will be most effective if aligned with the National Health Insurance goal, and extended to points of care nearest to patients where there is no resident dermatologist.

\subsubsection{Category: eHealth regulations}

The rules, rights and obligations of governments, companies, healthcare facilities, healthcare providers, and citizens can be set forth in a system of legal documents, also called a legal framework, and within that a regulatory framework. The legal weight or significance of different levels of direction or guidance varies (e.g., law, directive, policy). Regulations and standards are two common tools within a regulatory framework and are identified as design requirements. A regulation can be any guiding principle, rule, or law intended to control or govern the conduct of an entity. Standards are seldom regulations or laws, being simply an accepted or approved level of quality, performance, or achievement and against which others are judged or measured. Two design requirements were identified for the category of eHealth regulations: 


\section{TD regulations,}

2. TD standards.

TD regulations: A regulation or similar directive that required TD service provision as a routine healthcare practice would provide a clear mandate. Given that the literature provides evidence that TD can reduce referrals up to $75 \%$ (Mars \& Dlova, 2008) and that telemedicine, of which TD is one example, is feasible (Bashshur et al., 2016), the value proposition is evident. The evidence supports the need to examine and implement appropriate regulation to enable compliance to the Protection of Personal Information Act (POPI) and relevant laws (Republic of South Africa, 2004, 2013).

TD standards: Any telemedicine practice is expected to comply with available standards and guidelines (American Telemedicine Association, 2016; Krupinski \& Bernard., 2014), but as one interviewee noted that guidelines have been in draft form since 2008:

I'm not aware that the University or hospitals or, you know there's any other legal requirements, that's how it's been and it's been running like that for 8 to 10 years. (Clinician)

although telemedicine guidelines have since been approved (Health Professions Council of South Africa, 2014). Currently the use of mobile TD practice lacks appropriate guidelines (Mars \& Scott, 2017, 2015a). Conversely, available standards and guidelines need to be updated to include synchronous and asynchronous TD for fixed and mobile devices in South Africa. Jack and Mars highlighted the practical realities of obtaining informed telemedicine consent when a survey indicated that current face-to-face informed consent are not routinely obtained (Jack \& Mars, 2013). It has been suggested that such issues can be addressed by development of discipline specific guidelines for clinical, operational, technological, ethical, and regulatory issues for the practice of telemedicine (Jack \& Mars, 2008; Jack, 2013; Jack \& Mars, 2014). This was successfully done for telepsychiatry in South Africa and serves as an exemplar (Chipps, Ramlall, Madigoe, King, \& Mars, 2012). Constant review of current international guidance in this dynamic field (e.g., World Medical Association (2009)) is needed to resolve these issues prior to scale-up of TD, resulting in identification of TD standards as an important design requirement.

\subsubsection{Category: eHealth governance}

The study revealed questions of how TD for specialist dermatologist referrals in the public health sector is or may be directed and controlled, i.e., governed, and how TD scale-up could be aligned with governance decisions. The findings below were considered to collectively address a specific design requirement concerning TD alignment, reflecting the need to ensure that implementation of TD is aligned and prioritised (Benson, Bugnitz, \& Walton, 2004, p. 160-164) with current or planned national and provincial governance initiatives. 
TD alignment: Sources of insight included interviews, observation, expert opinion, and the literature, in particular South African standards related to governance of IT for organisations (South African Bureau of Standards, 2016). It was noted that while the national ICT governance roadmap was approved in 2013, KZN's Department of Health have not completed their own ICT governance strategy, which would allow ehealth and TD specific alignment to occur (South Africa Public Service and Administration, 2013). Other literature described how India aligned ICT based health services to governance practices (Nair, 2014). Experts also indicated that eHealth governance maturity provides an enabling environment for TD to be scaled and integrated into routine referral pathways.

Interviewees described the importance of aspects related to authority for planning, budgeting, and implementing eHealth interventions that would be considered governance issues. One interviewee reflected on the past ad hoc approach to introducing telehealth, saying:

I think a lot of them were based on a request basis ... and (they would) say we also want to try this videoconferencing and then from there the conversation would start. (Administrator)

Another interviewee commented on the value of having both a process and a committed person or persons leading the way:

You need to have an IT governance framework, then you need to have an IT Strategy

then you need to have lastly, it's the IT governance Champion. (Manager)

This was also highlighted in interviews confirming the need for, but lamenting the past ineffectiveness of, leadership groups to plan and guide the process. One emphasised:

need to have an IT Steering Committee, which we have (Manager)

while another noted

it never happens when all the stakeholders are available (Manager)

and another looked forward to a revival:

this year is to start/revive the eHealth Steering (Committee) (Manager)

These findings were considered to collectively address a specific design requirement concerning TD alignment.

\subsection{Theme: eHealth planning}

Stakeholder interviews (interviews), programme observations (observations), the literature, and expert opinion indicated that planning requires design requirements that ensure the TD scale-up approach is supported by TD information systems which form part of an eHealth information systems environment. Iterative review of these four sources of evidence (Table 4) resulted in four categories being identified within this theme: 
1. eHealth information systems

2. eHealth sustainability

3. eHealth benefits

4. eHealth program management

Within these a total of 10 specific design requirements were identified. Sections 4.3.1 to 4.3.4 describes the detail design requirements for all categories under theme 'eHealth planning'.

Table 4: Summary of data sources that provided inputs to theme 'eHealth planning' with supporting categories and requirements

\begin{tabular}{|c|c|c|c|c|c|}
\hline & Requirement name & Literature & Interviews & Observations & Expert opinion \\
\hline \multirow{4}{*}{$\begin{array}{l}\text { eHealth } \\
\text { information } \\
\text { systems }\end{array}$} & TD architecture & $\checkmark$ & & $\checkmark$ & $\checkmark$ \\
\hline & TD information security & $\checkmark$ & $\checkmark$ & $\checkmark$ & $\checkmark$ \\
\hline & TD automation & $\checkmark$ & $\checkmark$ & $\checkmark$ & $\checkmark$ \\
\hline & TD user interfaces & $\checkmark$ & & $\checkmark$ & $\checkmark$ \\
\hline \multirow{3}{*}{$\begin{array}{l}\text { eHealth } \\
\text { sustainability }\end{array}$} & TD sustainability & $\checkmark$ & & $\checkmark$ & $\checkmark$ \\
\hline & TD operational plan and budget & $\checkmark$ & $\checkmark$ & $\checkmark$ & $\checkmark$ \\
\hline & TD incentives & $\checkmark$ & $\checkmark$ & & $\checkmark$ \\
\hline eHealth & TD benefits realisation & $\checkmark$ & & & $\checkmark$ \\
\hline benefits & TD benefits communication & $\checkmark$ & $\checkmark$ & $\checkmark$ & $\checkmark$ \\
\hline $\begin{array}{l}\text { eHealth program } \\
\text { management }\end{array}$ & TD risk management & $\checkmark$ & $\checkmark$ & $\checkmark$ & $\checkmark$ \\
\hline
\end{tabular}

\subsubsection{Category: eHealth information systems}

The eHealth information systems category is a group of considerations towards development and integration of national eHealth information systems with four design requirements:

1. TD architecture

2. TD information security

3. TD automation

4. TD user interfaces

TD architecture: Currently there is no information technology architectural plan for TD (observations), and there is a need to ensure that TD can leverage existing or planned architecture such as the conceptual eHealth architecture (Fogwill, 2017; Moodley, Pillay, \& Seebregts, 2012), and other sources including National Health Laboratory Service (NHLS), Radiological Society of South Africa, UKZN Medical School, South African National Research Network (SANReN), and Council for Scientific and Industrial Research (CSIR) spectrum optimisation (Council for 
Scientific and Industrial Research, 2013). TD information technology architectural requirements exist (International Telecommunication Union-Telecommunication Development Sector (ITU-D), 2011; International Telecommunication Union-Telecommunication Standardisation Sector (ITUT), 2006), and should be defined and aligned with the national eHealth architecture to ensure interoperability (South Africa National Department of Health, 2014; South African Bureau of Standards, 2016).

TD information security: Healthcare data should be kept secure at all stages, from recording and capturing data through transmission, storage and retrieval of data, to backup. This principle is well documented in the literature, with examples such as the Health Insurance Portability and Accountability Act (HIPAA) in the USA, best practices in data security and management proposed by the Organisation for Economic Co-operation and Development (OECD), and guidance within South Africa (Organisation for Economic Co-operation and Development, 2015; Republic of South Africa, 2013; United States of America, 1996). Interviewees also raised their concern about the current state of mobile TD

should that information leak, we'll be sued. We'll be sued on the basis of POPI [Protection of Personal Information Act], that he did not get consent. (Manager)

This issue was also supported by the literature (Kanaan \& Carr, 2009) and expert opinion.

Interviewees raised further concern over security aspects and data stewardship for mobile TD, with one noting:

you don't know where the data is sitting, meaning you don't know how safe it is. (Manager)

This concern can exist for many types of data (patient records, photographs, instant messages, e-mails, etc.), as highlighted in another interview:

making sure also the legal aspect is water tight so that patient's pictures you don't have access to their pictures in cyberspace or wherever. Protection of patient's identity and confidentiality. (Clinician)

Observation also highlighted concerns regarding patient images and information on mobile devices, especially with mobile TD. Such concerns were also echoed through the global literature (Mars \& Scott, 2017, 2015a). Lessons for transmission encryption exist (Chakraborty, Gupta, \& Ghosh, 2013; Mat Kiah, Al-Bakri, Zaidan, Zaidan, \& Hussain, 2014) and for security frameworks (Caffery \& Smith, 2010; Zaidan et al., 2015). In South Africa the Protection of Personal Information (POPI) Act provides principles and processes for the secure and private recording, capturing, transmission, storage, retrieval and backup of patient data (Republic of South Africa, 2013).

Closely related to information security is ensuring the physical security of the information systems (data centres). The principles and processes to support information security have been described (e.g., Role-Based Access Control (RBAC)), but often lack adoption (Fernández-Alemán, 
Señor, Lozoya, \& Toval, 2013) and the advent of cloud computing adds complexity. System security plans and procedures should be formalised and implemented, and training provided to system users, in order to ensure that patient systems comply with POPI and related Acts and ensure good data stewardship for scaled-up TD.

TD automation: Programme observation showed that the majority of facilities have no hospital information system to electronically record patient information, with stand alone e-mails and data remaining on personal phones and other mobile devices or manual patient files that do not constitute part of a patient's electronic health record. South Africa has adopted standards that need to be adhered to when developing electronic health records (South Africa National Department of Health, 2014; South African Bureau of Standards, 2007a, 2007b). However, there are a number of developments in terms of automating and migrating from the manual paper-based clinic and hospital information systems to electronic health information systems (Geldenhuys \& Botha, 2015).

During interviews clinicians noted the importance of automating TD information systems in order to enhance the effectiveness and efficiency of the referral service. The dermatologists also wanted electronic access to a patient's history to aid informed diagnosis and treatment recommendations, and to record their findings from both fixed and mobile devices. For example, one interviewee stated:

if they [forms] were to be like computerised so everybody can access that, so you know you've seen the patient on this day, so if they say that this patient was seen before you can just log on pick up the patient on the system and then you continue from there. (Clinician)

Such approaches are also evident in the literature (Rubin \& Kovarik, 2015; Tensen et al., 2016). TD should be automated and integrated into a country's national electronic healthcare information systems.

TD user interfaces: User-friendly TD interfaces will promote the use of electronic information systems from both fixed and mobile platforms, since low computer literacy is a reality in South Africa (Mars \& Seebregts, 2008). Users value an interface that addresses their need seamlessly (Ouma, 2013). In addition the right input data enables health indicators to be measured and monitored towards realising provincial and national healthcare goals and objectives. The importance of human-centred design in effective human-computer interaction has been documented in the literature (Singh, Wünsche, \& Lutteroth, 2010). As TD is scaled-up it will be essential that information system interfaces are user friendly, able to input data from both fixed and mobile devices, and able to ensure data accuracy and completeness using structured input fields (International Telecommunication Union-Telecommunication Development Sector (ITU-D), 2011) 


\subsubsection{Category: eHealth sustainability}

Sustainability, in this context, speaks to attaining healthy lives for all (Division for Sustainable Development Goals UN-DESA, 2014). South Africa's National Health Insurance (South Africa National Department of Health, 2017) through striving for universal health coverage and South African eHealth Strategy (South Africa National Department of Health, 2012b) are aligned with this goal. Sustainability, the ability to be maintained or supported over the long-term, is one of the most important challenges for on-going TD referral since only a sustained service will meet on-going referral needs (Ndlovu, Littman-Quinn, Park, Dikai, \& Kovarik, 2014; Project Management Institute, 2016a). The need for TD sustainability was identified to assist public health management with ensuring sustainable scale-up of TD initiatives and is based on

deliberate efforts to increase the impact of successfully tested health innovations so as to benefit more people and to foster policy and programme development (World Health Organization, 2010a, p. 2)

in a sustainable manner. Achieving this is facilitated by creating a coherent and thoughtful plan solidly linked to an existing eHealth strategy.

TD sustainability: Simmons et al. emphasise: "Focus on sustainability even though this slows down the pace and scope of expansion" (2007, p. 151). The TD sustainability plan would both guide (address high priority activities; coordinate efforts) and form the basis of a reporting tool (tracking of progress) (Yellowlees, 2005).

TD operational plan and budget: Available literature and expert opinion indicated that within KZN there is currently no evidence to suggest that TD is funded under existing budget provisions (Walters et al., 2016). There is a need to lobby and plan for funding for both TD scale-up and sustained funding of TD services as a formal part of KZN's Department of Health plans and budgets. A TD operational plan and budget would provide the KZN Department of Health with detailed planning and affordability estimates of the required resources (time, people, infrastructure and finance) for a typical year of operations (Varndell, 2014; Ndlovu et al., 2014).

TD incentives: Providing incentives for healthcare professionals to adopt and use eHealth has been shown to be successful. For example, in the USA 'meaningful use' legislation has been applied as an incentive for use of electronic health records. Vo et al. (2015) have proposed a similar approach for telemedicine. The interviews also provided support for provision of incentives:

Dermatologists do not get overtime, but TD you can claim overtime. Incentivisation is possible. (Manager)

Zanaboni and Wootton highlighted incentives as a telemedicine adoption factor,

personal incentives for the health professionals involved in service provision are needed before the widespread adoption of telemedicine will occur. (2012, p. 1) 
Other literature provides further support for the use of incentives to attract and retain specialists such as dermatologists from the private sector to public health (South Africa National Department of Health, 2017; World Health Organization, 2010b).

The above collective evidence led to inclusion of TD sustainability, TD operational and plan and budget, and TD incentives as design requirements.

\subsubsection{Category: eHealth benefits}

The South African Medical Research Council (SAMRC) stated that the value proposition of telemedicine is recognised, but there is uncertainty as to how this value can be realised (South African Medical Research Council, 2011). When asked to describe the benefits of a functional TD service, one interviewee stated:

[it] means when you are seeing your patient, (even) though the specialist is not there with you, its there, because definitely if you have any problems ...your issue can be solved. (Clinician)

Another noted:

In the long run it will cut down workload of dermatologists, and care can be provided via TD. Dermatologists can then spend more time with patients and one would not wait 4 months to get an appointment. (Clinician)

The literature provides support for the value proposition (Whited, 2017) which TD holds both locally (Mars \& Dlova, 2008) and in Korea (Shin, Kim, Ryu, Yoon, \& Jo, 2014). Two design requirements were identified for the category of eHealth benefits:

1. TD benefits realisation

2. TD benefits communication

TD benefits realisation: The above values were identified as a component of benefits realisation management (BRM) (Bradley, 2010, p. 29). Consequently, adoption of a BRM approach (Serra \& Kunc, 2015) was identified as a means to assist with making the TD referral pathway efficient, effective, and equitable (South Africa National Department of Health, 2012a, 2017).

TD benefits communication: The fundamental importance of communication in the healthcare setting is appreciated (Rimal \& Lapinski, 2009). Communication of the TD scale-up benefits to stakeholders (particularly patients and healthcare providers) strengthens understanding of how an eHealth intervention contributes to healthcare provision, and health indicators (Project Management Institute, 2016b, 2017b). Scott and Saeed (2008) provide guidance on the development of eHealth indicators to effectively communicate the contributions of TD benefits. 


\subsubsection{Category: eHealth program management}

Successful scaling depends on effective management of the implementation and post scale-up (operational) risk of the program (Project Management Institute, 2017b). The design requirement 'TD risk management' was prioritised in this category as a key enabler for managing a scale-up program (Expert).

TD risk management: A key consideration for ensuring scaling of TD is to identify, communicate, and manage the associated risks that could negatively influence the success of scaling program during implementation and after operational integration (Institute of Electrical and Electronics Engineers, 2006; Jones \& Broomhead, 2011; Project Management Institute, 2009). Program observation highlighted the formalisation of scale-up risk management, patient consent, patient privacy, and patient rights, including consent for any technical support team. These observations identified 'TD risk management' as a necessary design requirement.

\subsection{Theme: eHealth action}

The theme 'eHealth action' requires design requirements to ensure that scale-up is supported by TD information systems that are integral to an eHealth information systems environment. Sources of insight included stakeholder interviews (interviews), programme observations (observations), the literature, and expert opinion (Table 5). Iterative review of the four sources of evidence resulted in two categories being identified within this theme; eHealth scale-up, and eHealth monitoring. Within these a total of 6 specific design requirements were identified. Sections 4.4.1 to 4.4.2 describe the detailed design requirements for all categories under theme 'eHealth action'.

Table 5: Summary of data sources that provided inputs to theme: 'eHealth action' with supporting categories and detail requirements

\begin{tabular}{llcccc}
\hline & Requirement name & Literature & Interviews & Observations & Expert opinion \\
\hline & TD mobilisation & $\checkmark$ & & & $\checkmark$ \\
eHealth & TD readiness & $\checkmark$ & & & $\checkmark$ \\
scale-up & TD training plan & $\checkmark$ & $\checkmark$ & $\checkmark$ & $\checkmark$ \\
& TD support plan & $\checkmark$ & $\checkmark$ & $\checkmark$ & $\checkmark$ \\
& TD finalisation & $\checkmark$ & & & $\checkmark$ \\
\hline and close-out & TD monitor \& control & $\checkmark$ & & $\checkmark$ & $\checkmark$ \\
\hline
\end{tabular}

\subsubsection{Category: eHealth scale-up}

The WHO describes scale-up as:

deliberate efforts to increase the impact of successfully tested health innovations so as to benefit more people and to foster policy and programme development on a lasting basis. (World Health Organization, 2010a, p. 2) 
Successful scaling depends on successful implementation. Five design requirements were identified that would support successful implementation:

1. TD mobilisation

2. TD readiness

3. TD training plan

4. TD support plan

5. TD finalisation and close out

TD mobilisation: An expert noted that ensuring successful scaling required confirmation that all planned and necessary resources (e.g., people, processes, budget, program schedules, and infrastructure) had been approved. This is supported by the National DoH, which states it is necessary to "mobilise resources for implementation of the eHealth strategy" (South Africa National Department of Health, 2012b, p. 29) and the Project Management Institute (Project Management Institute, 2017a).

TD readiness: Both expert opinion and the literature highlighted the importance of organisations and individuals being adequately prepared for implementation and scale-up, which is usually assessed by their level of readiness or preparedness (Chipps \& Mars, 2012; Project Management Institute, 2017a).

TD training plan: Evidence indicated it is necessary to ensure required end-user clinical, administrative and project team training activities are formally planned, budgeted, and implemented. The literature stated that a lack of detailed plans to guide the scale-up implementation process increased the risk that scale-up objectives might not be realised on time and within budget (Institute of Electrical and Electronics Engineers, 2009; Project Management Institute, 2017a). Similarly an Expert noted that adopting a coordinated approach to planning TD training between UKZN, KZN Department of Health and key role players would ensure that use of scarce resources is optimised.

TD support plan: Several sources identified the need to ensure that adequate and continuing support exists. One source identified the need for formal contracts and processes (South African Bureau of Standards, 2016) to support and maintain TD scale-up. Interviewees also expressed their concerns about this topic by reflecting on current IT support practice:

They're quite good, they do their best, they are very efficient. (Clinician)

However, it was noted that despite initially having IT support staff at rural referring sites, these posts were terminated, 
the Department of Health ... did not extend the contracts of whatever number of technicians and I think we had two hospitals that didn't have technicians because of the contract. (Administrator)

A desire for comprehensive support was expressed

There must be technical staff support on both ends. (Clinician)

In addition a Manager indicated there was an opportunity to leverage on existing support from UKZN, but that the Department of Health needed to formalise the relationship.

TD finalisation and closeout: The deliverables for a phase and supporting activities need to be formally accounted for on completion to allow for resource transitioning as necessary. This is in line with available literature, such as ISO/IEC/IEEE 16326:2009 (E), that states:

Items in the closeout plan should include a staff reassignment plan, a plan for archiving project materials, a plan for post-mortem debriefings of project personnel, and preparation of a final report to include lessons learned and analysis of project objectives achieved. (Institute of Electrical and Electronics Engineers, 2009, p. 11)

Similarly programme management guidelines indicate resources may be "ensure that program resources are appropriately released as program is being closed" (Project Management Institute, 2017b, p. 102).

\subsubsection{Category: eHealth monitoring}

The $\mathrm{I}(\mathrm{C}) \mathrm{T}$ governance literature also supported the need for the task of monitoring during and after scale-up implementation, to ensure correct and continued performance and conformance (South African Bureau of Standards, 2016). Mars and Seebregts (2008) identified the need to strengthen a 'data acquisition and analysis' culture (2008, p. 4). Further, Scott and Saeed described measurement of outcomes as appropriate practice when evaluating an eHealth activity, and that some of these indicators would transition into useful elements for monitoring performance (2008). Experts stated that monitoring provides valuable feedback on the utilisation of scarce resources and enabled corrective actions to be taken. The literature supported this view since there is a shortage of health information specialists to assist eHealth management with scaleup monitoring and controls (Mars \& Seebregts, 2008). Such evidence supported identification of 'TD monitor and control' as a design requirement within the category eHealth monitoring.

\section{TD monitor and control: Monitoring}

involves routinely obtaining information about progress against plans as well as the periodic examination of overall achievements against agreed strategies and outcomes to provide a basis for decision making and adjustments to plans (South African Bureau of Standards, 2016, p. 3) 
including checking that compliance with rules and regulations are adhered to. In addition control is active management actions that use implementation feedback to implement approved corrective measures to ensure scale-up objectives are met.

\section{SUMMARY OF TELEDERMATOLOGY SCALE-UP FRAMEWORK DESIGN RE- QUIREMENTS}

Based on the findings reported above a final set of TDSF design requirements were prepared, summarised in Table 1. These collectively provide an evidence-based guide for future identification or development of a TDSF. The findings of this study were supported through various types of evidence, including one or more of stakeholder interviews, programme observation, the literature, and expert opinion. This qualitative study used multiple data sources to gain an in-depth understanding of the needs for a TD scale-up framework and consequently strengthened the validity of the resultant design requirements. The insight gathered demonstrated the need for a TSDF to be built on certain principles and to possess certain characteristics. Thus, an optimal TDSF should be built in a structured manner from pilot projects to scaled implementation, and be holistic in addressing all aspects of the process while learning from previous scale-up attempts. It must be aligned with current or planned policy and strategic direction from the government, and address a clear evidenced-based health need. To ensure sustainability, it must be anchored in sound business and financial planning, and have evident leadership and stakeholder buy-in, as well as cultural and technological readiness. Active program risk and benefit management play a key role in successful scaling. Finally, on-going performance of the resulting service should be monitored and controlled.

The European Union has identified the need for development of a guide for "Telemedicine doers" to support the scale-up process (Jensen et al., 2015, p. ii). It is recognised that healthcare serves multiple stakeholders (South Africa National Department of Health, 2017), and eHealth programmes such as TD must be sustainable, and enhance the effectiveness and efficiency of dermatology referral pathways. Given this complexity a structured, holistic (Van Dyk, 2014; Van Gemert-Pijnen et al., 2011), and integrated approach to TDSF design, and scaling-up of TD is required. The approach should also incorporate aspects of benefits realisation (Bradley, 2010, p. 29; Serra and Kunc, 2015), project risk management (Jones \& Broomhead, 2011) and a clear communication strategy (Project Management Institute, 2016b) to ensure that the goal of scale-up remains visible and stakeholders stay informed.

The study findings provide an evidence-based understanding, including of what various users (stakeholders) of TD services consider to be necessary to provide a scaled and sustained TD service. Within KZN and South Africa it will be necessary for relevant facility, regional, and national departments to formalise (define, approve, align, and implement) processes and mechanisms that satisfactorily address each of the design requirements described. Such preparatory work will enhance the likelihood of success of integrating TD into routine clinical and administrative practice.

A limitation of this study was the lack of prioritisation of the design requirements once identi- 
fied. In addition it became apparent that careful interpretation of insight provided in interviews was necessary. Whilst some responses were illuminating and valuable, others revealed a lack of complete understanding of existing processes and procedures. Thus, the interviews provided perspective, but that perspective did not always reflect reality. As an example, concern was expressed about information and system security. In fact the KZN DoH has had ICT policies and practices in place for several years, but responses would suggest interviewees were unaware of this. Thus, the videoconferenced TD service does not go through the KZN Department of Health, as implied by some users. It is also ISDN-based and all data passes through CODECs for encryption and decryption. As a consequence whilst it may be correct for users to identify such data stewardship issues as a design requirement, system and information security are already considered. This also speaks to a clear need for enhanced awareness of, and communication with, users regarding all aspects of eHealth application.

The TDSF design requirements presented here are those for the public health sector in KwaZulu-Natal, having been derived - at least in part - from the insight of local TD stakeholders and observation of local TD programmes. Within the specific context of KZN and South Africa, the existence of documents such as the eHealth Strategy (South Africa National Department of Health, 2012b) imply much of the response to the identified design requirements will come from the national DoH who is responsible for overall healthcare governance (planning, budgeting, implementation), and thereby eHealth - and TD - governance. Communication of the study findings to the national DoH is appropriate. However, performance of a similar process in an alternate setting or for a different telehealth application is encouraged, since it would result in context specific design requirements.

\section{CONCLUSION}

To be certain that an eHealth intervention meets user expectations, aligns with their needs, and leads to sustainable integration into everyday healthcare, a requirements definition process is recommended. Here, a TDSF design requirements process and resulting design requirements have been presented. Collectively these represent the minimum design requirements for a TDSF, and will inform and assist the KwaZulu-Natal public health sector to identify or develop a suitable framework. Performance of a similar process in an alternate setting or for a different telehealth application would result in context specific design requirements.

\section{ACKNOWLEDGEMENTS}

Research reported in this publication acknowledges the contributions of the teledermatology stakeholders that participated in interviews and programme observations from KwaZulu-Natal Department of Health, University of KwaZulu-Natal's Department of Dermatology and the Department of TeleHealth. The research was supported by the Fogarty International Center of the National Institutes of Health under Award Number D43TW007004 and the Council for Scientific and Industrial Research, Meraka Institute, Pretoria, South Africa. The content is solely the responsibility 
of the authors and does not necessarily represent the official views of the National Institutes of Health or Fogarty International or the Council for Scientific and Industrial Research.

\section{References}

American Telemedicine Association. (2016). Practice guidelines for dermatology. Last accessed 19 Nov 2017. Retrieved from http://hub.americantelemed.org/resources/telemedicinepractice-guidelines?CLK=5c1536e8-2c94-4d54-ab39-8c1f64be3f9f

American Telemedicine Association. (2017). Quick guides for store-forward teledermatology and live-interactive teledermatology. Last accessed 15 Mar 2018. Retrieved from http://hub. americantelemed.org/resources/telemedicine-practice-guidelines? CLK $=5 c 1536 \mathrm{e} 8$ 2c94-4d54-ab39-8c1f64be3f9f

Barker, P., Reid, A., \& Schall, M. (2016). A framework for scaling up health interventions: Lessons from large-scale improvement initiatives in Africa. Implementation Science, 11(12). https: //doi.org/10.1186/s13012-016-0374-x

Bashshur, R., Howell, J., Krupinski, E., Harms, K., Bashshur, N., \& Doarn, C. (2016). The empirical foundations of telemedicine interventions in primary care. Telemedicine and $e$ Health, 22(5), 342-375. https://doi.org/10.1089/tmj.2016.0045

Bashshur, R., Shannon, G., Tejasvi, T., Kvedar, J., \& Gates, M. (2015). The empirical foundations of teledermatology: A review of the research evidence. Telemedicine and e-Health, 21(12), 953-979. https://doi.org/10.1089/tmj.2015.0146

Benson, R., Bugnitz, T., \& Walton, W. (2004). From business strategy to IT action: Right decisions for a better bottom line. John Wiley \& Sons, Inc.

Bradley, G. (2010). Benefit realisation management: A practical guide to achieving benefits through change (2nd). Farnham, Surrey, England: Gower Publishing Limited.

Caffery, L. \& Smith, A. (2010). A transmission security framework for email-based telemedicine. In A. Smith \& A. Maeder (Eds.), Studies in health technology and informatics (pp. 35-48). IOS Press. https://doi.org/10.1007/978-3-642-32355-3_8

Carruthers, J. (2013). Dermatology in South Africa. Dermatology World, 23(4), 14-16.

Chakraborty, C., Gupta, B., \& Ghosh, S. (2013). A review on telemedicine-based WBAN framework for patient monitoring. Telemedicine and e-Health, 19(8), 619-626. https://doi.org/ 10.1089/tmj.2012.0215

Chipps, J. \& Mars, M. (2012). Readiness of telepsychiatry health-care institutions in KwaZuluNatal to implement. Journal of Telemedicine and Telecare, 18(3), 133-137. https://doi. org/10.1258/jtt.2012.SFT103

Chipps, J., Ramlall, S., Madigoe, T., King, H., \& Mars, M. (2012). Developing telepsychiatry services in KwaZulu-Natal-An action research study. African Journal of Psychiatry (South Africa), 15(4), 255-263. https://doi.org/10.4314/ajpsy.v15i4.33

Christiansen, E., Henriksen, E., Lange, M., Lapão, L., Kaye, R., Knarvik, U., ... Whitehouse, D. (2015). Moving telemedicine from pilot to scale: 18 critical success factors. Last accessed 
15 Mar 2018. Retrieved from http://www.telemedicine-momentum.eu/wp-content/ uploads/2015/07/MomentumLeaflet2015-BlueprintInANutshell.pdf

Clarke, M. \& Mars, M. (2015). An investigation into the use of $3 \mathrm{G}$ mobile communications to provide telehealth services in rural KwaZulu-Natal. Telemedicine and e-Health, 21(2), 115119. https://doi.org/10.1089/tmj.2014.0079

Coates, S., Kvedar, J., \& Granstein, R. (2015a). Teledermatology: From historical perspective to emerging techniques of the modern era: Part I: History, rationale, and current practice. Journal of the American Academy of Dermatology, 72(4), 563-574. http://dx.doi.org/10. 1016/j.jaad.2014.07.061

Coates, S., Kvedar, J., \& Granstein, R. (2015b). Teledermatology: From historical perspective to emerging techniques of the modern era: Part II: Emerging technologies in teledermatology, limitations and future directions. Journal of the American Academy of Dermatology, 72(4), 577-586. https://doi.org/10.1016/j.jaad.2014.08.014

Cooley, L. \& Kohl, R. (2006). Scaling up-from vision to large-scale change: A management framework for practitioners. Last accessed 15 Mar 2018. Retrieved from http://www . msiworldwide.com/files/scalingup-framework.pdf

Council for Scientific and Industrial Research. (2013). ICT Research Development and Innovation Roadmap. Last accessed 15 Mar 2018. Retrieved from http://www.meraka.org.za/ ictroadmap/sites/default/files/Roadmap\%20-\%20DEV12.pdf

Cruickshank, J. \& Beer, G. (2010). Healthcare without walls: A framework for delivering telehealth at scale. Last accessed 15 Mar 2018. Retrieved from http://www.2020health.org/ 2020health/Publications/Publications-2010/telehealth.html

Division for Sustainable Development Goals UN-DESA. (2014). Introduction and proposed goals and targets on Sustainable Development for the Post2015 development agenda: Zero Draft rev 1. Last accessed 15 Mar 2018. Retrieved from http://sustainabledevelopment.un.org/ content/documents/4523zerodraft.pdf

Fernández-Alemán, J., Señor, I., Lozoya, P. O., \& Toval, A. (2013). Security and privacy in electronic health records: A systematic literature review. Journal of Biomedical Informatics, 46(3), 541-562. https://doi.org/10.1016/j.jbi.2012.12.003

Fogwill, T. (2017). Conceptual architecture for eHealth interoperability. Paper presented at the Interoperability Expert Group Meeting, 30 June 2017, Pretoria, South Africa.

Geldenhuys, P. \& Botha, A. (2015). On the design of an electronic health patient registration system for South Africa. In J. Steyn \& J. van Belle (Eds.), Beyond development. Time for a new ICT4D paradigm? 9th IDIA conference IDIA2015, Nungwi, Zanzibar. (pp. 202-216).

Gulube, S. \& Wynchank, S. (2001). Telemedicine in South Africa: Success or failure? Journal of Telemedicine and Telecare, 7(2), 47-49. https://doi.org/10.1258/1357633011937100

Gulube, S. \& Wynchank, S. (2002). The national telemedicine system in South Africa-An overview and progress report. South African Medical Journal, 92(7).

Gulube, S., Wynchank, S., Lotz, J., Beningfield, S., Hurribance, A., Mathews, L., ... Rutherfoord, G. (1999). Telemedicine-Redressing South Africa's health care imbalance. South African Medical Journal, 89(6), 623-624. 
Health Professions Council of South Africa. (2014). Guidelines for good practice in the healthcare professions: General ethical guidelines for good practice in telemedicine. Last accessed 15 Mar 2018. Retrieved from http:// www.hpcsa.co.za/Uploads/ editor / UserFiles / downloads/conduct_ethics/Booklet\%2010.pdf

Hussein, R. (2015). A review of realizing the Universal Health Coverage (UHC) goals by 2030: Part 1-Status quo, requirements, and challenges. Journal of Medical Systems, 39(71). https: //doi.org/10.1007/s10916-015-0254-y

Institute of Electrical and Electronics Engineers. (2006). ISO/IEC 16085:2006, Standard for Software Engineering - Software Life Cycle Processes-Risk Management. https://doi.org/10. 1109/IEEESTD.2006.288594

Institute of Electrical and Electronics Engineers. (2009). ISO/IEC/IEEE 16326-2009 International Standard - Systems and Software Engineering - Life Cycle Processes - Project Management. https://doi.org/10.1109/IEEESTD.2009.5372630

Institute of Electrical and Electronics Engineers. (2011). ISO/IEC/IEEE 29148:2011(E) Systems and software engineering-Life cycle processes - Requirements engineering. https:// doi . org/10.1109/IEEESTD.2011.6146379

International Telecommunication Union-Telecommunication Development Sector (ITU-D). (2011). Scaling e-Health services in step with ICT transformation. Last accessed 15 Mar 2018. Retrieved from https://www.itu.int/ITU-D/cyb/app/docs/Scaling\%20e-Health-E.pdf

International Telecommunication Union-Telecommunication Standardisation Sector (ITU-T). (2006). FSTP-RTM: Roadmap for telemedicine (Series F: Non-Telephone Telecommunication Services). Last accessed 15 Mar 2018. Retrieved from http://handle.itu.int/11.1002/pub/ 80316902-en

Jack, C. (2013). Telehealth / eHealth / mHealth: Transforming the client/physician relationshipsThe legal and ethical issues. (Doctoral dissertation, University of KwaZulu-Natal, Durban, South Africa).

Jack, C. \& Mars, M. (2008). Telemedicine a need for ethical and legal guidelines in South Africa. South African Academy of Family Practice/Primary Care, 50(2), 60a-60d. https://doi.org/ 10.1080/20786204.2008.10873698

Jack, C. \& Mars, M. (2013). Informed consent for telemedicine in South Africa: A survey of consent practices among healthcare professionals in Durban, KwaZulu-Natal. South African Journal of Bioethics and Law, 6(2), 55-59. https://doi.org/10.7196/sajbl.287

Jack, C. \& Mars, M. (2014). Ethical considerations of mobile phone use by patients in KwaZuluNatal: Obstacles for mHealth? African Journal of Primary Health Care and Family Medicine, 6(1), 7. https://doi.org/10.4102/phcfm.v6i1.607

Jensen, L., Knarvik, U., Pedersen, C., Tangene, W., \& Whitehouse, D. (2015). Deliverable 3.4 personalised blueprint for telemedicine deployment: Validated and tested version. Last accessed 15 Mar 2018. Retrieved from http://www.telemedicine-momentum.eu/wpcontent/uploads/2015/02/D3.4_v1.0_ValidatedBlueprint.pdf

Jones, T. \& Broomhead, S. (2011). eHealth and managing risk-A white paper. Last accessed 15 Mar 2018. Retrieved from http://tintree.org/whitepapers/Managing\%20Risk.pdf 
Kanaan, S. \& Carr, J. (2009). Health data stewardship: What, why, who, how. An NCVHS Primer. Last accessed 15 Mar 2018. Retrieved from https://www.ncvhs.hhs.gov/wpcontent/uploads/2014/05/090930lt.pdf

Khoja, S., Scott, R., Casebeer, A., Mohsin, M., Ishaq, A., \& Gilani., S. (2007). e-Health readiness assessment tools for healthcare institutions in developing countries. Telemedicine and eHealth, 13(4), 425-432. https://doi.org/10.1089/tmj.2006.0064

Krupinski, E. \& Bernard., J. (2014). Standards and guidelines in telemedicine and telehealth. Healthcare, 2(1), 74. https://doi.org/10.3390/healthcare2010074

Leigh-Hunt, N. (2016). The impact of political, economic, socio-cultural, environmental and other external influences. Education, CPD and revalidation from phast. Last accessed 13 Mar 2018. Retrieved from https://www.healthknowledge.org.uk/public-health-textbook/ organisation-management/5b-understanding-ofs/assessing-impact-external-influences

Major, J. (2005). Telemedicine room design. Journal of Telemedicine and Telecare, 11(1), 10-14. https://doi.org/10.1177/1357633X0501100103

Mars, M. (2013). Telemedicine and advances in urban and rural healthcare delivery in Africa. Progress in Cardiovascular Diseases, 56(3), 326-335. https://doi.org/10.1016/j.pcad. 2013.10.006

Mars, M. \& Dlova, N. (2008). Teledermatology by videoconference: Experience of a pilot project. South African Academy of Family Practice/Primary Care, 50(3), 70-70d. https://doi.org/ 10.1080/20786204.2008.10873725

Mars, M. \& Scott, R. (2015a). Spontaneous adoption of mobile phone technology for m-dermatology - caution. Paper presented at the Global Telehealth 2015: Integrating Technology and Information for Better Healthcare, May 29-30, Toronto, Canada.

Mars, M. \& Scott, R. (2015b). Spontaneous telemedicine services-What can we learn? In F. Lievens \& M. Jordanova (Eds.), Global Telemedicine and eHealth Updates: Knowledge Resources Vol. 8 (pp. 229-232). International Society for Telemedicine \& eHealth (ISfTeH). Retrieved from http://www.medetel.lu/download/2015/parallel_sessions/presentation/ day2/Mars_Spontaneous_telemedicine.pdf

Mars, M. \& Scott, R. (2017). Being spontaneous: The future of telehealth implementation? Telemedicine and e-Health, 23(9). https://doi.org/10.1089/tmj.2016.0155

Mars, M. \& Seebregts, C. (2008). Country case study for e-Health South Africa. Making the eHealth connection. Last accessed 15 Mar 2018. Retrieved from http://ehealth-connection. org / files / resources / County \% 20Case \% 20Study \% 20for \% 20 eHealth \% 20South \% 20Africa.pdf

Martin, C. (2011). Telemedicine room design program guide. Last accessed 15 Mar 2018. Retrieved from http://www.telehealthresourcecenter.org/sites/main/files/file-attachments/090824-2_ctec_program_guide-room_design_w_cm_edits.pdf

Mat Kiah, M., Al-Bakri, S., Zaidan, A., Zaidan, B., \& Hussain, M. (2014). Design and develop a video conferencing framework for real-time telemedicine applications using secure groupbased communication architecture. Journal of Medical Systems, 38(133). https://doi.org/ 10.1007/s10916-014-0133-y 
Moodley, D., Pillay, A., \& Seebregts, C. (2012). Position paper: Researching and developing open architectures for National Health Information Systems in developing African countries. In Z. Liu \& A. Wassyng (Eds.), Foundations of Health Informatics Engineering and Systems. FHIES 2011. (pp. 129-139). LNCS 7151. https://doi.org/10.1007/978-3-642-323553_8

Naidoo, S. \& Mars, M. (2015). Telemedicine in the public sector in South Africa: An overview (vol. 8). Last accessed 15 Mar 2018. Retrieved from https://www.isfteh.org/files/media/ Global_Telemedicine_and_eHealth_Updates_2015.pdf

Nair, P. (2014). ICT based health governance practices: The Indian experience. Journal of Health Management, 16(1), 25-40. https://doi.org/10.1177/0972063413518678

Ndlovu, K., Littman-Quinn, R., Park, E., Dikai, Z., \& Kovarik, C. (2014). Scaling up a mobile telemedicine solution in Botswana: Keys to sustainability. Frontiers in Public Health, 275. https://doi.org/10.3389/fpubh.2014.00275

Office for the Advancement of Telehealth. (2015). What is a hybrid consultation? Last accessed 15 Mar 2018. Retrieved from http://www.telehealthresourcecenter.org/toolbox-module/ types-telemedicine-specialty-consultation-services-what-is-a-hybrid-consultation

Organisation for Economic Co-operation and Development. (2015). Health data governance: Privacy, monitoring and research. OECD Publishing. http://dx.doi.org/10.1787/9789264244566-en.

Ouma, S. (2013). M-health user experience framework for the public healthcare sector (Doctoral dissertation, Nelson Mandela Metropolitan University (NMMU), Port Elizabeth).

Project Management Institute. (2009). Practise standard for project risk management. Last accessed 15 Mar 2018. Retrieved from https://www.pmi.org/pmbok-guide-standards/ framework/practice-standard-project-risk-management

Project Management Institute. (2016a). Benefits realization management framework-PMI Thought Leadership Series Report. Last accessed 15 Mar 2018. Retrieved from http://www.pmi.org//media/pmi/documents/public/pdf/learning/thought-leadership/benefits-realizationmanagement-framework.pdf

Project Management Institute. (2016b). Strengthening benefits awareness in the C-suite: Benefits realization management-PMI Thought Leadership Series Report. Last accessed 15 Mar 2018. Retrieved from http://www.pmi.org/-/media/pmi/documents/public/pdf/ learning/thought-leadership/strengthen-benefits-awareness-csuite.pdf

Project Management Institute. (2017a). A guide to the project management body of knowledge (PMBOK Guide) (6th). Project Management Institute, Inc. Retrieved from https://www. pmi.org/pmbok-guide-standards/foundational/pmbok/sixth-edition

Project Management Institute. (2017b). The standard for program management (4th). Project Management Institute.

Republic of South Africa. (2004). National health act 61 2003, 26595. Last accessed 15 Mar 2018. Retrieved from http://www2.saflii.org/za/legis/hist_reg/nha6102003rangnr636590/ nha6102003rangnr636a20j2007691.html 
Republic of South Africa. (2013). Protection of Personal Information Act 2013, Act No. 4 of 2013. Last accessed 15 Mar 2018. Retrieved from https://www.acts.co.za/protection-ofpersonal-information-act-2013/act

Rimal, R. \& Lapinski, M. (2009). Why health communication is important in public health. Bulletin of the World Health Organization, 87(4), 247. https://doi.org/10.2471/BLT.08. 056713

Rubin, C. \& Kovarik, C. (2015). The nuts and bolts of teledermatology: Preventing fragmented care. Journal of the American Academy of Dermatology, 73(5), 886-888. https://doi.org/ 10.1016/j.jaad.2015.06.046

Saunders, M., Lewis, P., \& Thornhill, A. (2016). Research methods for business students (7th). Pearson Education Ltd.

Schonenberg, H., Pauws, S., Bescos, C., Westerteicher, C., Maramis, C., Filos, D., ... Roca., J. (2014). Evaluation framework for care coordination and telehealth deployment. In 7th International Conference on Health Informatics, HEALTHINF 2014 - Part of 7th International Joint Conference on Biomedical Engineering Systems and Technologies, BIOSTEC 2014, Angers, Loire Valley; France; 3 March 2014 through 6 March 2014; Code 105595 (pp. 358$365)$.

Scott, R. \& Mars, M. (2013). Principles and framework for e-Health strategy development. Journal of Medical Internet Research, 15(7), e155. https://dx.doi.org/10.2196\%2Fjmir.2250

Scott, R. \& Saeed, A. (2008). Global ehealth-Measuring outcomes: Why, What, and How. A report Commissioned by the World Health Organization's Global Observatory for eHealth. Last accessed 15 Mar 2018. Retrieved from http://www.ehealth-connection.org/files/ conf-materials/Global\%20eHealth\%20-\%20Measuring\%200utcomes_0.pdf

Serra, C. \& Kunc, M. (2015). Benefits realisation management and its influence on project success and on the execution of business strategies. International Journal of Project Management, 33, 53-66. https://doi.org/10.1016/j.ijproman.2014.03.011

Shin, H., Kim, D., Ryu, H., Yoon, S., \& Jo, S. (2014). Teledermatology consultation using a smartphone multimedia messaging service for common skin diseases in the Korean army: A clinical evaluation of its diagnostic accuracy. Journal of Telemedicine and Telecare, 20(2), 70-74. https://doi.org/10.1177/1357633X14524151

Simmons, R., Fajans, P., \& Ghiron, L. (2007). Scaling up health service delivery: From pilot innovations to policies and programmes. Last accessed 15 Mar 2018. Retrieved from http:// www.expandnet.net/PDFs/Scaling-Up_Health_Service_Delivery-WHO-ExpandNet.pdf

Simon, H. (1996). The sciences of the artificial (3rd). MIT Press.

Singh, J., Wünsche, B., \& Lutteroth, C. (2010). Framework for Healthcare4Life-A ubiquitous patient-centric telehealth system. In CHINZ '10 Proceedings of the 11th International Conference of the NZ Chapter of the ACM Special Interest Group on Human-Computer Interaction, CHINZ 2010, Auckland (pp. 41-48). Association for Computing Machinery. https: //doi.org/10.1145/1832838.1832846

South Africa National Department of Health. (2012a). A telemedicine strategy for South Africa 2012-2016: Draft for consultation. 
South Africa National Department of Health. (2012b). National eHealth strategy South Africa 2012/13-2016/17. Last accessed 15 Mar 2018. Retrieved from http://www. health.gov . za/index.php/2014-08-15-12-54-26/category/95-2012s?download=171: ehealthstrategy-south-africa-2012-2016

South Africa National Department of Health. (2014). National health normative standards framework for interoperability in eHealth - Gazette version. Last accessed 15 Mar 2018. Retrieved from http://hufee.meraka.org.za/Hufeesite/staff/staff/the-hufee-group/paula-kotze1/hnsf-government-gazette

South Africa National Department of Health. (2017). National health insurance for South Africa: Towards universal health coverage. Last accessed 15 Mar 2018. Retrieved from http://www. gov.za/sites/www.gov.za/files/40955_gon627.pdf

South Africa Public Service and Administration. (2013). Implementation of the corporate governance of information and communication technology policy framework in the South African public service. Last accessed 15 Mar 2018. Retrieved from http://www.dpsa.gov.za/ dpsa2g/documents/psictm/2013/Directive_Policy_04_02_2013.pdf

South African Bureau of Standards. (2007a). SANS 18308:2007 Health informatics - Requirements for an electronic health record architecture. Last accessed 15 Mar 2018. Retrieved from https://store.sabs.co.za/catalogsearch/result/?q=18308

South African Bureau of Standards. (2007b). SANS 20514:2007 Health informatics-Electronic health record-Definition, scope and context. Last accessed 15 Mar 2018. Retrieved from https://store.sabs.co.za/catalogsearch/result/?q=18308

South African Bureau of Standards. (2016). SANS 38500:2016 Information technology - Governance of IT for the organization. Last accessed 15 Mar 2018. Retrieved from https://store.sabs. co.za/catalogsearch/result/?q=38500

South African Medical Research Council. (2011). Media statement. Last accessed 15 Mar 2018. Retrieved from http://www.mrc.ac.za/pressreleases/2011/12press2011.htm

Tensen, E., van der Heijden, J., Jaspers, M., \& Witkamp, L. (2016). Two decades of teledermatology: Current status and integration in national healthcare systems. Current Dermatology Reports, 5(2), 96-104. https://doi.org/10.1007/s13671-016-0136-7

Thurmond, V. (2001). The point of triangulation. Journal of Nursing Scholarship, 33(3), 253-258. https://doi.org/10.1111/j.1547-5069.2001.00253.x

Tyler, J. (2001). The healthcare information technology context: A framework for viewing legal aspects of telemedicine and teleradiology. In Proceedings of the 34th Annual Hawaii International Conference on System Sciences, 2001. https://doi.org/10.1109/HICSS.2001. 926562

United States of America. (1996). Health insurance portability and accountability act of 1996. Last accessed 15 Mar 2018. Retrieved from https://aspe.hhs.gov/report/health-insuranceportability-and-accountability-act-1996

Van Dyk, L. (2014). A review of telehealth service implementation frameworks. International Journal of Environmental Research and Public Health, 11(2), 1279-1298. https://doi.org/ 10.3390/ijerph110201279 
Van Gemert-Pijnen, E., Nijland, N., Van Limburg, M., Ossebaard, C., Kelders, M., Eysenbach, G., \& Seydel, R. (2011). A holistic framework to improve the uptake and impact of Health technologies. Journal of Medical Internet Research, 13(4), e111. https://www.jmir.org/ 2011/4/e111/

Van Velsen, L., Wentzel, J., \& Van Gemert-Pijnen, E. (2013). Designing eHealth that matters via a multidisciplinary requirements development approach. JMIR Research Protocols, 2(1), e21. https://doi.org/10.2196/resprot.2547

Varndell, J. (2014). ICT4Health business case for mhealth. Paper presented at the ICT4Health 2014 Conference, 10 - 11 November, Durban, South Africa.

Vo, A., Shore, J., Waugh, M., Doarn, C., Richardson, J., Hathaway, O., ... Thomas, M. (2015). Meaningful use: A national framework for integrated telemedicine. Telemedicine and eHealth, 21(5), 355-363. https://doi.org/10.1089/tmj.2014.0142

Wade, V. \& Eliott, J. (2012). The role of the champion in telehealth service development: A qualitative analysis. Journal of Telemedicine and Telecare, 18(8), 490-492. https://doi. org/10.1258/jtt.2012.gth115

Walters, L., Mars, M., \& Scott, R. (2016). A review and critique of teledermatology in the South African public health sector. In A. J. Maeder, K. Ho, A. Marcelo, \& J. Warren (Eds.), The promise of new technologies in an age of new health challenges (pp. 143-151). IOS Press. https://doi.org/10.3233/978-1-61499-712-2-143

Whited, J. (2017). Summary of the status of teledermatology research. Last accessed 15 Mar 2018. Retrieved from https://higherlogicdownload.s3.amazonaws.com/AMERICANTELEMED/ 3c09839a-fffd-46f7-916c-692c11d78933/UploadedImages/SIGs/2017\%20Summary\% 20of\%20the\%20Status\%20of\%20Teledermatology\%20Research.pdf

Whitten, P. \& Adams, I. (2003). Success and failure: A case study of two rural telemedicine projects. Journal of Telemedicine and Telecare, 9(3), 125-129. https://doi.org/10.1258/ 135763303767149906

World Health Organization. (2010a). Nine steps for developing a scaling-up strategy. Last accessed 15 Mar 2018. Retrieved from http://www.who.int/immunization/hpv/deliver/nine_ steps_for_developing_a_scalingup_strategy_who_2010.pdf

World Health Organization. (2010b). The world health report: Health systems financing-The path to universal coverage. Last accessed 15 Mar 2018. Retrieved from http://apps.who. int/iris/bitstream/10665/44371/1/9789241564021_eng.pdf

World Health Organization. (2011). Beginning with the end in mind: Planning pilot projects and other programmatic research for successful scaling up. Last accessed 28 Jun 2018. Retrieved from https : / / www . expandnet. net / PDFs / ExpandNet - WHO \% 20 - \%20Beginning \% 20with\%20the\%20end\%20in\%20mind\%20-\%202011.pdf

World Medical Association. (2009). WMA statement on guiding principles for the use of telehealth for the provision of health care. Last accessed 15 Mar 2018. Retrieved from https: //www.wma.net/policies-post/wma-statement-on-guiding-principles-for-the-use-oftelehealth-for-the-provision-of-health-care/ 
Yellowlees, P. (2001). An analysis of why telehealth systems in Australia have not always succeeded. Journal of Telemedicine and Telecare, 7(2), 29-31. https://doi.org/10.1258/ 1357633011937056

Yellowlees, P. (2002). Government relations, government regulations: Jumping through the hoops. Journal of Telemedicine and Telecare, 8(3), 83-85. https://doi.org/10.1258/13576330260440970.

Yellowlees, P. (2005). Successfully developing a telemedicine system. Journal of Telemedicine and Telecare, 11(7), 331-335. https://doi.org/10.1258/135763305774472024

Zaidan, B., Haiqi, A., Zaidan, A., Abdulnabi, M., Mat Kiah, M., \& Muzamel, H. (2015). A security framework for nationwide health information exchange based on telehealth strategy. Journal of Medical Systems, 39(51). https://doi.org/10.1007/s10916-015-0235-1

Zanaboni, P. \& Wootton, R. (2012). Adoption of telemedicine: From pilot stage to routine delivery. BMC Medical Informatics and Decision Making, 12(1), 1-9. https://doi.org/10.1186/ 1472-6947-12-1 